COGNITIVE SCIENCE 4, 47-70 (1980)

\title{
The Intentionality of Intention and Action*
}

\author{
JoHN R. SEARLE \\ University of California, Berkeley
}

\begin{abstract}
Cognitive Science is likely to make little progress in the study of human behavior until we have a clear account of what a human action is. The aim of this paper is to present a sketch of a theory of action. I will locate the relation of intention to action within a general theory of Intentionality. I will introduce a distinction between prior intentions and intentions in actions; the concept of the experience of acting; and the thesis that both prior intentions and intentions in action are causally selfreferential. Each of these is independently motivated, but together they enable me to suggest solutions to several outstanding problems within action theory (deviant causal chains, the accordian effect, basic actions, etc.), to show how the logical structure of intentional action is strikingly like the logical structure of perceptions, and to construct an account of simple actions. A successfully performed intentional action characteristically consists of an intention in action together with the bodily movement or state of the agent which is its condition of satisfaction and which is caused by it. The account is extended to complex actions.
\end{abstract}

\section{I}

What exactly are the relationships between the intention I had at the time of the last election to vote for Jones and the action that I performed when I did vote for Jones? And what exactly are the relations between these and the desire I had at the time of the last election to vote for Jones, or the belief that I had at that time that I would vote for Jones? It is quite commonly said that actions are caused by beliefs and desires, but if that is so, then what role do intentions play? On the face of it, actions would appear to be caused by intentions, and an argument for this view would be that intentions enable us to justify counterfactuals in a way

*I am indebted to Julian Boyd, Hubert Dreyfus, Dagmar Searle. Bruce Vermazen and Steve White for comments on earlier drafts of this paper. 
that is typical of causal phenomena: e.g. if I hadn't intended to vote for Jones at the last election, I wouldn't have voted for him. But if we say that intentions cause actions, then what happens to beliefs and desires? Can they still be causes too? And if so, how does their causal role relate to that of intentions? What is an action anyhow? I think that the problems of the relation of action and intention is one of the messiest tangles of puzzles in contemporary philosophy and the aim of this paper is to unravel at least part of the tangle.

Since my method of achieving that aim will be to locate the relation of intention and action within a general theory of Intentionality, I need to begin with a brief account of Intentional states. Intentional states are directed at or about objects and states of affairs in the world-states such as beliefs, hopes, fears, desires and intentions. All Intentional states consist of a representative content in a psychological mode. Thus, for example, I can hope that you will leave the room, fear that you will leave the room or believe that you will leave the room, and in each case we have the same representative content, expressed by "that you will leave the room" in a different psychological mode-hope, fear, or belief. The form of such Intentional states we can therefore symbolize as $S(r)$, where the " $S$ " is a variable for psychological mode and " $r$ " for representative content. ${ }^{2}$ Furthermore, such Intentional states as these can be said to be satisfied or not satisfied depending on whether the representative content actually matches or represents anything in reality. Thus if I believe that you will leave the room and you do indeed leave the room, my belief is said to be true, and if I fear that you will leave the room and you do leave the room, my fear is not said to be true but to have been realized. If I hope that you will leave the room and you do leave the room, my hope is said to have been fulfilled. "True" and "false" are used to assess success in representing states of affairs in the mind-to-world direction, of fit, and terms like "fulfilled" and "realized" are used to assess success in representing states of affairs in the world-to-mind direction of fit. Beliefs have the mind-to-world direction of fit, desires and intentions have the world-to-mind direction of fit. Intuitively the idea of direction of fit is that if the fit doesn't come off, one side or the other is amiss. If my belief is false, my belief is at fault, not the world (hence mind-to-world direction of fit); if my desires are unfulfilled it is the world that disappoints me (hence world-to-mind direction of fit). Not every Intentional state has a direction of fit. If, for example, I am sorry that you left the

'The account which follows is a very brief summary of the theory of Intentionality advanced in Searle (1971 \& 1979). In order to distinguish the technical sense of "Intentionality" from the ordinary English intend, intention, etc., I will capitalize the technical occurrences.

${ }^{2}$ In what follows I will frequently use this form to represent Intentional states. Thus, e.g., the desire reported by "I want to go to the movies" will be represented as

I want (I go to the movies)

and the content of the desire simply by

(I go to the movies). 
room, my sorrow has no direction of fit, though it does contain the belief that you left the room and the wish that you had not left the room, and that belief and wish have directions of fit. Indeed if the belief is not satisfied (i.e. true) then my sorrow is misplaced or inappropriate. The state of affairs that makes the Intentional state with a direction of fit satisfied I call its conditions of satisfaction. Where the conditions of satisfaction contain actual things (objects, events, etc.) I call these the Intentional objects of the Intentional states. But if we are to allow ourselves to speak in the jargon of "Intentional objects," it is important to emphasize that they have no special ontological status: they are just the objects which Intentional states happen to be about. Thus, for example, if I believe that Carter is a Democrat, the conditions of satisfaction of my belief are that Carter is a Democrat and the Intentional object is Carter, but if I believe that the King of France is bald, my belief has no Intentional object. We might summarize this brief account by saying that the key to understanding Intentionality is representation, and the key to understanding representation is conditions of satisfaction. All Intentional states with a direction of fit represent their conditions of satisfaction (there will be some refinements on these views later). ${ }^{3}$

Now at first sight the relation between intention and action seems to fit nicely into this general account of Intentionality. As we will see later, we are inclined to say: just as my belief is satisfied iff the state of affairs represented by the content of the belief actually obtains, and desire is satistied iff the state of affairs represented by the content of the desire comes to pass, so my intention is satisfied iff the action represented by the content of the intention is actually performed. If I believe that I will vote for Jones, my belief will be true iff I vote for Jones, if I desire to vote for Jones my desire will be fulfilled iff I vote for Jones, and if I intend to vote for Jones my intention will be carried out iff I vote for Jones. Besides these "semantic" parallels, there are also syntactical parallels in the sentences reporting intentional states. Leaving out problems of tense, the deep structure of the three sentences reporting my belief, desire, and intention respectively are:

$$
\begin{aligned}
& \text { I believe + I vote for Jones. } \\
& \text { I want + I vote for Jones. } \\
& \text { I intend + I vote for Jones. }
\end{aligned}
$$

We ought to be impressed by the apparent tightness of fit between the syntax and semantics: each sentence represents an Intentional state; each state represents its conditions of satisfaction and these conditions are represented by the sentence "I vote for Jones", which is exactly the embedded sentence in the sentences representing the Intentional states. The latter two sentences, but not the

${ }^{3} \mathrm{Also}$, for purposes of this exposition, I am confining my discussion to the so-called propositional attitudes and ignoring those Intentional states such as love and hate that don't normally have whole propositions as representative contents 
first, permit an equi NP deletion of the repeated "I" and the insertion of the infinitive in the surface structure, this:

I want to vote for Jones.

I intend to vote for Jones.

Furthermore, the way in which intention and action fit into this general account of Intentionality enables us to give a simple (but provisional) statement of the relations between intentions and intentional actions: an intentional action is simply the realization of the conditions of satisfaction of an intention. On this view anything that can be the satisfaction of an intention can be an intentional action. Thus, for example, spilling one's beer is not normally the condition of satisfaction of an intention, because people don't normally spill their beer intentionally: but such a thing can be an intentional action, for it can be the condition of satisfaction of an intention.

As it stands this account won't quite work, because it seems to admit too much. For example, if I intend to weigh 160 pounds by Christmas and I succeed, it won't do to say I performed the intentional action of weighing 160 pounds by Christmas nor will it do to say that weighing 160 pounds by Christmas can be an intentional action. What one wants to say rather is that if I fulfilled my intention to weigh 160 pounds by Christmas, I must have performed certain actions $b y$ means of which I came to weigh 160 pounds; and that needs to be further explained. Furthermore, the account says nothing about general intentions. But worse yet, this account seems to have very little explanatory power: what we want to know is, what is an intention? What is an action? And what is the character of the relation between them that is described by saying that one is the condition of satisfaction of the other? Still, I believe this provisional account is on the right track and I will come back to it later.

One advantage of it, by the way, is that it ties in with our intuition that there is a close connection between intentional actions and what one can tell people to do. Since when one gives orders, one orders people to perform intentional actions, one can only order people to do things that they can do intentionally, and indeed it does not make any clear sense to say "I order you to perform $A$ unintentionally."

\section{II}

So far we seem to be moving quite smoothly in our efforts to assimilate action and intention to a theory of Intentionality. However, now our troubles begin. There are some interesting asymmetries between the relation of intention to action on the one hand and the relation between the other Intentional states and their conditions of satisfaction on the other. A theory of intention and action ought to be able to explain them.

To begin with, it ought to strike us as odd that we have a special name such a "action" and "act" for the conditions of satisfaction of intentions at all. We 
have, for example, no special names for the conditions of satisfaction of beliefs and desires. Furthermore, the connection between what is named and the Intentional state which it satisfies is much more intimate in the case of intentions than in such other states as beliefs and desires. We saw that my belief will be satisfied iff the state of affairs I believe to obtain really does obtain, and my desire will be satisfied iff the state of affairs I desire to obtain does obtain, and, similarly, my intention to do an action will be satisfied iff the action I intend to perform actually is performed. But notice that whereas there are lots of states of affairs which are not believed to obtain or desired to obtain, there are no actions without intentions. Even where there is an unintentional action such as Oedipus 's marrying his mother, that is only because there is an identical event which is an action he performed intentionally, namely marrying Jocasta. There are many states of affairs without corresponding beliefs and many states of affairs without corresponding desires but there are in general no actions without corresponding intentions. ${ }^{4}$ Why should there be this asymmetry?

Furthermore, even though an event represented in the content of my intention occurs, it isn't necessarily the satisfaction of my intentions. As many philosophers have remarked, it has to come about "in the right way, " and this again has no analogue for beliefs and desires. Thus, if I believe it's raining and it is raining, my belief is true no matter how it got to be raining. And if my desire is to be rich and I become rich, that desire is satisfied no matter how I got rich.

But a variation on an example of Chisholm (1966, p. 37) will show that this condition does not hold for actions. Suppose Bill intends to kill his uncle, then it might come about that he kills his uncle and yet the conditions of satisfaction of his intention do not obtain. They may not obtain even in some cases where his intention to kill his uncle actually caused him to kill his uncle. Suppose he is out driving thinking about how he is going to kill his uncle, and suppose his intention to kill his uncle makes him so nervous and excited that he accidentally runs over and kills a pedestrian who happens to be his uncle. Now in this case it is true to say that he killed his uncle and true to say that his intention to kill his uncle was (part of) the cause of his killing his uncle, but not true to say that he carried out his intention to kill his uncle or that his intention was satisfied because he didn't kill his uncle intentionally.

III

In this section I want to develop an account of the relations between intention and action that will both show how the relations fit into the general theory of Inten-

${ }^{4}$ On my account such things as snoring, sneezing, sleeping, and many reflex movements are not actions. Whether or not I am right about ordinary usage is less important than whether I can give an account of intention and action that shows such cases to be fundamentally different from those that I count as actions. 
tionality sketched in Section I and yet account for the paradoxical features of the relation of action and intention discussed in Section II. For the sake of simplicity I will start with very simple actions such as raising one's arm. Later I will consider more complex cases. In this article I will say nothing about purely mental actions, though I think the account can be extended to them as well.

We need first to distinguish those intentions that are formed prior to actions and those that are not. The cases we have considered so far are cases where the agent has the intention to perform the action prior to the performance of the action itself, where, for example, he knows what he is going to do because he already has an intention to do that thing. But not all intentions are like that: suppose you ask me, "When you suddenly hit that man, did you first form the intention to hit him?" My answer might be, "No, I just hit him". But even in such a case I hit him intentionally and my action was done with the intention of hitting him. I want to say about such a case that the intention was in the action but that there was no prior intention. The characteristic linguistic form of expression of a prior intention is "I will do $A$ " or "I am going to do $A$ ". The characteristic form of expression of an intention in action is "I am doing $A$ ". We say of a prior intention that the agent acts on his intention, or that he carries out his intention, or that he tries to carry it out. But in general we can't say such things of intentions in action, because the intention in action just is the Intentional content of the action; the action and the intention are inseparable in ways that I will shortly try to explain.

There are at least two ways to make the distinction between an intention in action and a prior intention clearer. The first, as our previous example suggests, is to note that many of the actions one performs, one performs quite spontaneously, without forming, consciously or unconsciously, any prior intention to do those things. For example, suppose I am sitting in a chair reflecting on a philosophical problem and I suddenly get up and start pacing about the room. My getting up and pacing about are clearly intentional actions, but in order to do them I do not need to form an intention to do them prior to doing them. I don't in any sense have to have a plan to get up and pace about. Like many of the things one does, I just do these actions; I just act. A second way to see the same distinction is to note that even in cases where I have a prior intention to do some action there will normally be a whole lot of subsidiary actions which are not represented in the prior intention but which are nonetheless performed intentionally. For example, suppose I have a prior intention to drive to my office. As I am carrying out this prior intention I might perform a series of subsidiary actions for which I need not have formed a prior intention: opening the door, starting the engine, depressing the clutch, etc. When I formed my intention to drive to the office I might not have given these subsidiary acts a thought. Yet such actions are intentional. For such cases I have an intention, but no prior intentions.

All intentional actions have intentions in action but not all intentional actions have prior intentions. I can do something intentionally without having 
formed a prior intention to do it, and I can have a prior intention to do something and yet not act on that intention. Still, in cases where the agent is acting on his prior intention there must be a close connection between the prior intention and the intention in action, and we will also have to explain this connection.

Prior intentions are selfreferential in the sense that the representative content of the intention refers to the intention of which it is a part. This thesis can be illustrated with the following example. Suppose I intend to raise my arm. The content of my intention can't be that my arm goes up, for my arm can go up without me raising my arm. Nor can it be simply that my intention causes my arm to go up, for we saw in our discussion of the uncle example that a prior intention can cause a state of affairs represented by the intention without that state of affairs being the action that would satisfy the intention. Nor, oddly enough, can it be

(that I perform the action of raising my arm)

because I might perform the action of raising my arm in ways that had nothing to do with this prior intention. I might forget all about this intention and later raise my arm for some other independent reason. The representative content of my intention must be

(that I perform the action of raising my arm by way of carrying out this intention).

Now this formulation raises lots of questions we will need to answer later: what is meant by "action", what is meant by "carrying out," and what is the exact role of the selfreference?

In the meantime, this selfreferential character of intentions will seem less mysterious if we compare it with a similar phenomenon in the realm of speech acts (and incidentally it is always a good idea when you get stuck in the theory of Intentionality to go back to speech acts, because the phenomena of speech acts are so much more accessible). Suppose I order you to leave the room. And suppose you respond by saying "I am going to leave the room, but not because you ordered me to, I was just about to leave the room anyhow. But I would not have left the room because you ordered me to. "If you then leave the room, have you obeved my order? Well, you certainly didn't disobey the order, but there is a sense in which you did not obey it either, because the order did not function as a reason for what you did. We would not, for example, on the basis of a series of such cases describe you as an "obedient" person. But what this illustrates is that the content of my order is not simply that you leave the room, but that you leave the room by way of obeying this order: that is, the logical form of the order is not simply

I order you (that you leave the room)

but rather it is selfreferential in the form 
I order you (that you leave the room by way of obeying this order). ${ }^{5}$

In order to examine intentions in action I need to say a little more about different forms of Intentionality. I said before that such Intentional states as beliefs, fears, desires, etc. are representations of their conditions of satisfaction: but not all forms of Intentionality really sit comfortably with this account, and one form which does not is perception. Suppose I am seated in front of a table and $I$ see the table. In so doing I will have a visual experience of the table. But now the visual experience is not identical with the table, for I don't see the visual experience. I see the table, and I have the visual experience when I see the table. "But," someone might say in the style of classical epistemology, "suppose that the experience is an hallucination and there is nothing there. What do you see then?" And the answer is: when I have the visual experience but there is no table there, I see nothing. I have the visual experience and thus it seems to me as if I were seeing the table, but I do not in fact see anything. But now notice, and this is the crucial point, the visual experience has Intentionality, and the argument for this is that even when I am having an hallucination, I know what the hallucination is an hallucination of: that is, I know what must be the case in order that this experience not be an hallucination, and to say that is just to say that in having the visual experience I know its conditions of satisfaction. The conditions of satisfaction are that there should be a table there, and additionally that it should have such and such properties and should cause my visual experience. Part of the difference between the Intentionality of a state like belief and the Intentionality of visual experience is that the visual experience is not a representation of the object, but one might say, a presentation of the object. When I see an object I directly perceive it and do not represent it to myself.

So, the truth conditions of a sentence of the form " $x$ saw a table " involve two components (besides $x$ ), a visual experience and a table; but the two are not independent, for the visual experience is a presentation of the table. And that is another way of saying that the Intentionality of the visual experience is such that its conditions of satisfaction require that there be a table there and that the table play a certain sort of causal role in the production of the visual experience. Subtract the fact that there is a table there from the event of seeing the table and what is left is a visual experience, but the visual experience is not a neutral "sense datum," it has Intentionality, and its Intentionality is presentational rather than representational. Just to have a clear distinction in terminology I will use "visual perception" as the name of the complex event that involves both the Intentional component and its conditions of satisfaction, and I will use "visual experience" as the name of the Intentional component.

${ }^{5}$ The selfreference does not lead to an infinite regress. When I order you to do $A, I$ am indeed creating a reason for your doing $A$ such that the order will be obeyed iff you do $A$ for that reason, i.e. because I ordered you to do it: but I do not in addition create a reason for it to be a reason, nor do I give a second-level order to you to obey my first-level order. 
Now let us apply all this to Wittgenstein's (1953) question: If I raise my arm, what is left over if I subtract the fact that my arm went up? The question seems to me exactly analogous to the question: If I see the table what is left over if I subtract the table? And in each case the answer is that a certain form of presentational Intentionality is left over, but the direction of fit and the direction of causation is different in the two cases. When I raise my arm I have a certain experience, and like my visual experience of the table, this arm-raising experience has a certain form of Intentionality, it has conditions of satisfaction. For if I have this experience and my arm doesn't go up, the Intentional content of the experience is not satisfied. Furthermore, even if my arm goes up, but goes up without this experience, I didn 't raise my arm, it just went up. That is, just as the case of seeing the table involves two related components, an Intentional component (the visual experience) and the Intentional "object" or conditions of satisfaction of that component (the table), so the act of raising my arm involves two components, an Intentional component (the experience of acting) and the Intentional "object" "or conditions of satisfaction of that component (the movement of my arm). As far as Intentionality is concerned the differences between the visual experience and the experience of acting are in the direction of fit and in the direction of causation: the visual experience stands to the table in the mind-toworld direction of fit. If the table isn't there, we say that I was mistaken, or was having an hallucination, or some such. And the direction of causation is from the object to the visual experience. If the Intentional component is satisfied it must be caused by the object. But in the case of the experience of acting, the Intentional component has the world-to-mind direction of fit. If I have this experience but the event doesn't occur we say such things as that I failed to raise my arm, or that I tried to raise my arm but did not succeed. And the direction of causation is from the experience of acting to the event. Where the Intentional content is satisfied, that is, where I actually succeed in raising my arm, the experience of acting causes the arm to go up. If it didn't cause the arm to go up, but something else did, I didn't raise my arm; it just went up for some other reason. And just as the visual experience is not a representation of its conditions of satisfaction but a presentation of those conditions, so I want to say, the experience of acting is a presentation of its conditions of satisfaction. On this account, action, like perception, is a causal and Intentional transaction between mind and the world.

Now, just as we don't have a name for that which gives us the Intentional content of our visual perception but have to invent a term of art, "the visual experience," so there is no term for that which gives us the Intentional content of our intentional action, but have to invent a term of art, "the experience of acting." But the term would mislead if it gave the impression that I thought that such things were passive experiences or sensations that simply afflict one, or that they were like what some philosophers have called volitions or acts of willing or anything of that sort. They are not acts at all, for we no more perform our experience of acting than we see our visual experiences. Nor am I claiming that 
there is any special feeling that belongs to all intentional actions. There are (at least) two ways to come to understand what I am driving at. Suppose you were in a situation where you couldn't perceive your arm, and suppose someone gave you the order to raise your arm and you carried out that order. Now if in such a case we subtract the fact that your arm goes up, what we have left over is what I am calling the experience of acting. What is left over will normally involve certain feelings and bodily sensations, but for our purposes the phenomenal properties of these sensations and feelings are not what matters, rather what matters are the logical properties of the experience, and the logical properties are that the experience in question has certain conditions of satisfaction and those conditions of satisfaction are internal to the experience in the sense that it couldn 't be that experience if it didn't have those conditions of satisfaction and there is no way to have that experience without knowing that it has those conditions of satisfaction.

And this last point leads to the second way to try to clarify this notion. It is generally the case, as several philosophers ${ }^{6}$ have remarked, that at any point in a man's waking life he is doing something; there is an answer to the question, what is he doing now? But also, and we ought to allow ourselves to be struck by this fact, at any point in a man's conscious life he knows what he is doing. A man knows without observation the answer to the question, what are you doing now? He may of course make all sorts of mistakes and blunders: he may think he is stirring pancake batter when in fact he is grinding peanuts, but even in such a case he knows what he is trying to do. Now the knowledge of what one is doing in this sense, in the sense in which such knowledge does not guarantee that one knows that one is succeeding, and does not depend on any observations that one makes of oneself, characteristically derives from one 's awareness ${ }^{7}$ of the conditions of satisfaction of the experience of acting. And, again, the parallel with perception holds. Just as at any point in a man's conscious life he knows the answer to the question, "What are you doing now?" so he knows the answer to the question, "What do you see now?' In both cases the knowledge in question is simply an awareness of the conditions of satisfaction of a certain sort of presentation.

Anyone who is still in doubt about the existence of the sort of phenomena I am describing as the experience of acting would do well to ponder the distinction

${ }^{6}$ See, for example, Hampshire. 1959.

${ }^{7}$ Again my use of phrases like "knowledge of the cunditions of satisfaction" or "awareness of the conditions of satisfaction " will be misleading if we do not prevent two sorts of misunderstanding at the outset. First, I do not mean that we are always thinking about or conscious of the conditions of satisfaction. If you say to me "What exactly are you doing now?" I may say "I am passing the green Chevrolet on the right." But that needn "t imply that I was thinking about or conscious of passing the green Chevrolet before you ask me the question. Secondly, knowledge or awareness of the conditions of satisfaction are not second-order Intentional states. If they were, we would get an infinite regress. 
between intentional actions and the sorts of cases described by Dr. W. Penfield (1975):

When I have caused a conscious patient to move his hand by applying an electrode to the motor context of one hemisphere I have of ten asked him about it. Invariably his response was: "I didn't do that. You did. "When I caused him to vocalize, he said, "I didn't make that sound. You pulled it out of me." (p. 76)

There is clearly a difference between the case where the patient moves his hand in an intentional action and the case where the patient's hand moves as a result of Penfield's electrical stimulation of his brain. But since the physical movements in the two cases are identical, what exactly is the difference? And how does the patient know in one case that he is moving his hand and in the other that he is not doing anything ("I didn't do that. You did"). And as an answer to these questions I am suggesting that first there is an obvious phenomenal difference between the case where one moves one's hand and the case where one observes it move independently of one's intentions-the two cases just feel different to the patient - and secondly that this phenomenal difference carries with it a logical difference in the sense that the experience of moving one's hand has certain conditions of satisfaction. Such concepts as "trying," "succeeding, " and "failing" apply to it in ways that they do not apply to the experiences the patient has when he simply observes his hand moving. Now this experience with its phenomenal and logical properties I am calling the experience of acting. And I am not claiming that there is a characteristic experience common to every intentional action, but rather that for every intentional action there is the experience of performing that action, and that experience has an Intentional content.

The parallel between the Intentionality of visual perception and the Intentionality of Intentional action can be made explicit as in Table 1.

TABLE 1

\begin{tabular}{|c|c|c|}
\hline & Visual perception & Intentional action \\
\hline Intentional component & visual experience & experience of acting \\
\hline $\begin{array}{l}\text { Conditions of satisfaction of the } \\
\text { Intentional component }\end{array}$ & $\begin{array}{l}\text { that there be objects, states of } \\
\text { affairs, etc. and that these have } \\
\text { certain features and certain } \\
\text { causal relations to the visual } \\
\text { experience }\end{array}$ & $\begin{array}{l}\text { that there be certain bodily } \\
\text { movements, states, etc., of the } \\
\text { agent, and that these have cer- } \\
\text { tain causal relations to the ex- } \\
\text { perience of acting }\end{array}$ \\
\hline Direction of fit & mind-to-world & world-to-mind \\
\hline Direction of causation & $\begin{array}{l}\text { world-to-mind (i.e. the object } \\
\text { causes the experience) }\end{array}$ & $\begin{array}{l}\text { mind-to-world (i.e. the experi- } \\
\text { ence causes the movements, } \\
\text { etc.) }\end{array}$ \\
\hline $\begin{array}{l}\text { Corresponding features of the } \\
\text { world }\end{array}$ & objects and states of affairs & $\begin{array}{l}\text { movements, and states involv- } \\
\text { ing the agent }\end{array}$ \\
\hline
\end{tabular}


So far I have tried to establish three claims: first, that there is a distinction between prior intentions and intentions in action: secondly, that prior intentions are selfreferential; and thirdly, that the action, for example, of raising one's arm, contains two components-the experience of acting, which has a form of Intentionality that is both presentational and causal, and the event of one's arm going up. Next I want to put these conclusions into a general account of the relations of prior intentions, intentions in action, and actions.

The Intentional content of the intention in action and the experience of acting are identical. Indeed as far as Intentionality is concerned the experience of acting just is the intention in action. The only difference between them is that the experience may have certain phenomenal properties that are not essential to the intention. In exactly the same way the visual experience has the same Intentionality as its presentational content but the experience has certain phenomenal properties that are not essential to that Intentionality (as the Weiskrantz (1977) experiments indicate) ${ }^{8}$

Our problem now is to lay bare the relations between the following four elements: the prior intention, the intention in action (the experience of acting), the bodily movement, and the action. The method is to take a simple example and make fully explicit the Intentional contents of the two intentions. Now why is that the method? Because our aim is to explain the relations between intentions and actions; and since an action is, in some sense at least, the condition of satisfaction of the intention to perform it, any attempt to clarify these relations must make completely explicit how the Intentional content of the intentions represents (or presents) the action (or the movement) as their conditions of satisfaction. And this method differs somewhat from the standard methods of the philosophy of action because we don't stand way back away from the action and see which descriptions we can make of it, we have to ge! right up close to it and see what these descriptions are actually describing. The other method incidentally produces such true but superficial results as that an action "can be intentional under one description, but not intentional under another" - one might as well say that a fire engine can be red under one description but not red under another. What one wants to know is: What facts exactly are these various descriptions describing? What fact about the action makes it "intentional under one description" and what fact about it makes it "not intentional under another?"

Suppose I recently had a prior intention to raise my arm and suppose, acting on that intention, I now raise my arm. How does it work? The representative content of the prior intention can be expressed as follows:

(I perform the action of raising my arm by way of carrying out this intention.)

${ }^{8}$ Briefly, Weiskrantz's (1977) studies concem patients who have hrain lesions that produce "blind sight:" they are able to report events that occur in their visual fields but they report no visual experience of these events. They thus have the Intentionality of the visual experience without the accompanying phenomenal properties. 


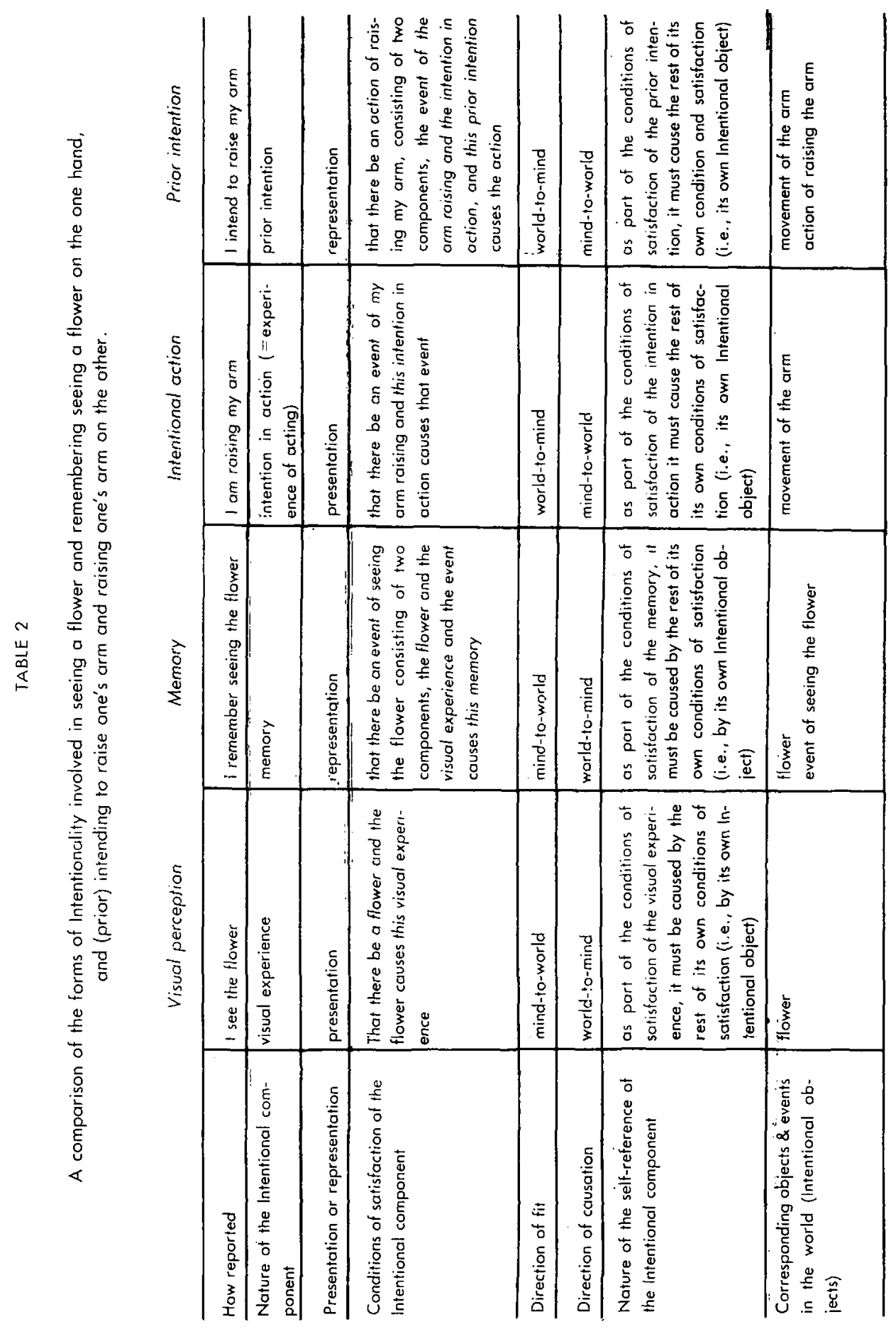


The prior intention thus makes reference to the whole action as a unit, not just the movement, and it is selfreferential. But the action as we have seen contains two components, the experience of acting and the movement; where the Intentional content of the experience of acting and the intention in action are identical. The next step then is to specify the Intentional content of the intention in action and show the relation of its Intentional content to that of the prior intention. The presentational content of the intention in action is:

\section{(My arm goes up as a result of this intention in action.)}

Now at first sight the contents of the prior intention and the intention in action look quite different, because the prior intention represents the whole action in its conditions of satisfaction, but the intention in action presents, but does not represent, the physical movement and not the whole action as its conditions of satisfaction. In the former case the whole action is the "Intentional object" in the latter case the movement is the "Intentional object." The intention in action is selfreferential in the sense that its Intentional content determines that it is satisfied only if the event that is its Intentional object is caused by it. Another difference is that in any real life situation the intention in action will be much more determinate than the prior intention, it will include not only that my arm goes up but that it goes up in a certain way and at a certain speed, etc. ${ }^{y}$

Well, if the content of the prior intention and the Intention in action are so different, how do they ever-so to speak - get together? In fact the relationship is quite simple, as we can see by unpacking the content of the prior intention and making explicit the nature of the selfreference of the prior intention. Since the whole action is represented as a unit by the prior intention and since the action consists of two components, the experience of acting and the physical movement, in order to make the content of the prior intention fully explicit, we can represent each component separately. Furthermore, the nature of the selfreference of the prior intention is (like the selfreference of the intention in action)

${ }^{9}$ The relative indeterminacy of prior intentions is most obvious in the case of compiex actions. In our earlier examples of carrying out my intention to drive to my office, there will be a large number of subsidiary acts that are not represented by the prior intention but are presented by the intentions in action: I intentionally start the engine, shift gears, pass slow-moving vans, stop at red lights, swerve to avoid cyclists, change lanes - and so on with dozens of subsidiary acts that are performed intentionally but need not have been represented by my prior intention. This difference has also been a source of confusion in philosophy. Several philosophers have remarked that not everything I do intentionally is something I have an intention to do. For example, the particular movements of my hand when I brush my teeth are done intentionally, even though I had no intention to do them. But this view is a mistake that derives from a failure to see the difference between prior intentions and intentions in action. I may have had no prior intention to make just these hand movements but I had an intention in action to make them. 
causal. ${ }^{10}$ The prior intention causes the intention in action which causes the movement. By transitivity of causation we can say that the prior intention causes both the intention in action and the movement, and since this combination is simply the action, we can say that the prior intention causes the action. The way to see this is to see that if we break the causal connection between the prior intention and the intention in action we no longer have an action which is a case of carrying out that intention, even though the action may have been performed intentionally. Suppose I intend to raise my arm in thirty seconds, and suppose I forget all about that intention in such a way that it plays no role, conscious or unconscious, in my subsequent behavior. Suppose in thirty seconds I raise my arm "just for the hell of it." In such a case I had a prior intention to raise my arm and I did raise my arm but since the prior intention played no causal role in my raising my arm I didn't carry out that intention. This also enables us to see what was wrong in the Chisholm-style counterexample I presented earlier. Bill had the prior intention to kill his uncle and his intention caused him to kill his uncle but his prior intention didn't cause an intention in action that presented the killing of his uncle as Intentional content, it just presented his driving his car or some such. (More about this later.) Since, as we have seen, the form of selfreference of the prior intention is causal and since the representation of the action can be split into two components, the Intentional content of the prior intention can now be expressed as follows:

(I have an intention in action which is a presentation of my arm going up, which causes my arm to go up, and which is caused by this prior intention).

And thus the prior intention causes the intention in action. By transitivity of causation, the prior intention represents and causes the entire action, but the intention in action presents and causes the bodily movement.

I think these points can be made clearer by pursuing our analogy with perception a bit farther. Roughly speaking, the prior intention to raise my arm is to the action of raising my arm as the memory of seeing the flower is to seeing the flower; or, rather, the formal relations between the memory, the visual experience of the flower, and the flower are the mirror images of the formal relations between the prior intention, the intention in action, and the bodily movement. The seeing consists of two components, the visual experience and the flower, where the flower causes the visual experience and the visual experience has the flower as Intentional object. The visual experience is of the flower, and it is selfreferential in the sense that unless the flower causes this experience the conditions of satisfaction do not obtain; i.e. I do not actually see the flower. The

${ }^{10}$ It is perhaps worth emphasizing that this view does not imply determinism. When one acts on one 's desires or carries out one's prior intention, the desire and intention function causally, but it is not necessarily the case that one could not have done otherwise, that one simply could not help oneself. 
memory of seeing the flower represents both the visual experience and the flower, and is selfreferential in the sense that unless the memory was caused by the visual experience which in turn was caused by the flower, I didn't really remember seeing the flower. Now similarly the action consists of two components, the experience of acting and the movement as Intentional object. The experience of acting is of the movement of my arm, and it is selfreferential in the sense that unless the movement is caused by this experience the conditions of satisfaction do not obtain; i.e. I do not actually raise my arm. The prior intention to raise my arm represents both the experience of acting and the movement, and is selfreferential in the sense that unless this intention causes the experience of acting which in turn causes the movement, I don't really carry out my prior intention. These relations can be made explicit by expanding our earlier table into Table 2.

A few things about Table 2 are worth special mention. First, neither the memory nor the prior intention is essential to the visual perception or the intentional action respectively. I can see a lot of things that I have no memory of seeing and $I$ can perform a lot of intentional actions without any prior intention to perform those actions. Secondly, the asymmetry of the direction of fit and the direction of causation is too neat to be accidental. Put crudely the intuitive explanation is this: when I try to make the world be the way I want it to be, I succeed if the world comes to be the way I want it to be (world-to-mind direction of fit), but only because I make it be that way (mind-to-world direction of causation). Analogously, if I see the world the way it really is (mind-to-world direction of fit), it is only because the way the world is makes me see it that way (world-to-mind direction of causation). Thirdly, for the sake of simplicity I have left out of Table 2 the fact that the conditions of satisfaction of the Intentional components will contain various details about what the flower looks like and how the raising of the arm is performed. I have not tried to include everything. Fourthly, the formal structure of the table is not meant to suggest that perception and action function independently of each other. For most complex actions, such as driving a car or eating a meal, I have to be able to perceive what I am doing in order to do it: and similarly there is an intentional element in most complex perceptions, as when I am looking at a painting or feeling the texture of a rug. Fifthly, because of the transitivity of causation, I have allowed myself to oscillate between saying the memory of seeing the flower is caused by the event of seeing the flower and the memory of seeing the flower is caused by the visual experience which is in turn caused by the flower. Similarly I oscillate between saying the prior intention causes the action and the prior intention causes the intention in action which causes the movement. Since in each case the complex event contains a component which is both Intentional and causal, and since in each case the Intentional component stands in certain causal relations to another Intentional state which represents the whole complex event, it doesn't seem to me to matter which of the two ways of speaking we adopt. 
Before showing how this account solves the problems of Section II, I want to tie up a few loose ends.

If intentions really cause actions in the way described, then why is it that we can't normally explain an action by stating its intention? If I am asked, "Why did he raise his arm?" it sounds odd to say: "Because he intended to raise his arm." The reason it sounds odd is because by identifying the action as "raising his arm" we have already identified it in terms of the intention in action. We already reveal an implicit knowledge that the cause of the arm going up was the Intentional component in the action of raising it. But notice it doesn't sound at all odd to specify the intention in action as the cause of the movement: why did his arm go up? He raised it. Nor does it sound odd to give some further intention as the cause of the action. Why did he raise his arm? He was voting / waving goodbye / reaching for the book / exercising / trying to touch the ceiling. This is what people are driving at when they say that we can often explain an action by redescribing it. But if we redescribe it truly there must be some facts we are redescribing which were left out of our first description, and these facts are that the action has an Intentional component which was left out of the first description and which causes the other component, e.g. his prior intention to vote by raising his arm causes his intention in action of raising his arm which causes his arm to go up. Remember, on this account all actions consist of an Intentional component and a "physical" (or other sort of) Intentional object component. We can always explain this non-Intentional component by the Intentional component, and the Intentional component can be as complex as you like. Why is that man wriggling around like that? He's sharpening an axe. But to say he's sharpening an axe is to say his action has at least two components, an axe-sharpening intention in action and the series of movements caused by that intention. But we can't answer the question, "Why is he sharpening an axe?" by identifying that intention, because we have already identified the axe-sharpening intention when we asked the question. But we can say, e.g., he's preparing to chop down a tree.

What do people mean when they say that an action can be "intentional under one description but not intentional under another?" The action consists of two components, an Intentional component and its Intentional object, the intention in action is the Intentional component and it presents the Intentional object as its conditions of satisfaction. But the complex event which constitutes the action will also have all sorts of other features not presented as a part of the Intentional content of the intention in action. Oedipus intended to marry Jocasta but when he married Jocasta he was marrying his mother. "Marrying his mother" was not part of the Intentional content of the intention in action, but it happened anyhow. The action was intentional under the description "marrying Jacosta," it was not intentional under the description "marrying his mother." But all that means is that the total action had elements which were parts of the conditions of satisfaction of the intention in action and other elements which were not. It is misleading to state these facts about actions in terms of descriptions of actions because it 
suggests that what matters is not the action but the way we describe the action, whereas, according to my account, what matters are the facts that the descriptions describe.

This distinction will be clearer if we consider intentional actions performed by animals, and it is no more puzzling, incidentally, to ascribe intentional actions to animals than it is to ascribe visual perceptions to them. Suppose my dog is running around the garden chasing a ball: he is performing the intentional action of chasing the ball and the unintentional action of tearing up the Lobelias, but this has nothing to do with anybody's descriptions. The dog certainly can 't describe himself, and the facts would remain the same whether or not any human being ever did or could describe them. The sense in which one and the same event or sequence of events can be both an intentional action and an unintentional action has no intrinsic connection with linguistic representation but rather with Intentional presentation. Some aspects of the event may be conditions of satisfaction of the Intentional content, some other aspects may not: and under the first set of aspects the action is intentional, under the second set, not: even though there need be nothing linguistic about the way an Intentional content presents its conditions of satisfaction.

A question I don't know the answer to is, how do we distinguish between those features of the complex event which are unintentional actions and those features which are so far from the intention that they are not actions at all? When Oedipus married his mother he moved a lot of molecules, caused some neurophysiological stuff in his brain, and altered his spatial relationship to the North Pole. These are all things he did unintentionally and none of them are actions of his. Yet I feel inclined to say that marrying his mother, though it was something he did unintentionally, was still an action, an unintentional action. Perhaps the reason for this difference in our (my) intuitions is that the description "marrying his mother" is closer to the content "marrying Jocasta" than is "moving a lot of molecules." I think that there must be a principle in operation here, but $I$ do not know what it is.

We have so far been talking mostly about very simple cases such as raising one's arm and I will now very briefly sketch how this account could be extended to account for complex intentions and the relations between complex intentions, the accordion effect (see Feinberg, 1970, p. 134) and basic actions (see Danto, 1968, pp. 43-58).

Consider Gavrilo Princip and his murder of the Archduke in Sarajevo. Of Princip we say that he:

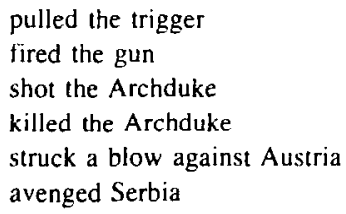


Furthermore, for each member of this list we can say that it is the action by means of which the next member is achieved. Thus he fired the gun by means of pulling the trigger, he shot the Archduke by means of firing the gun, etc. Now to the extent that each of these descriptions expresses the content of an intention in action we can say that under each description the action is intentional. Furthermore, the representation of the by-means-of relation forms a part of the content of the complex intention. Thus he intended to strike a blow against Austria by means of killing the Archduke, which action he intended to perform by means of shooting the Archduke, which he intended to perform by means of firing the gun, etc. Starting in the middle we can extend the accordion up or down by earlier or later members of the sequence of intentions. But notice that we can't go on indefinitely. As far as the causal story is concerned there are lots of things that happened up above the top, down below the bottom, and off to the side which are not part of the accordion. Thus we could add to the list as follows:

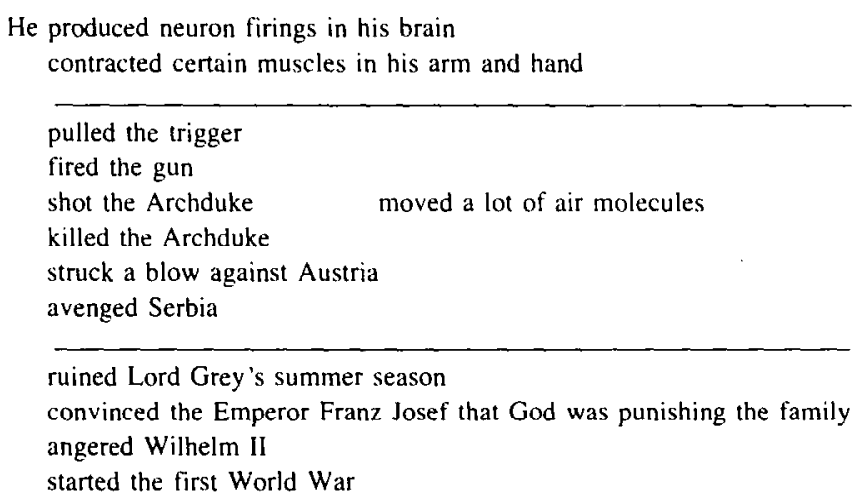

But none of these things above, below or to the side are Intentional actions of Princip, and I am inclined to say none of them are actions of his at all. They are just unintended things that happened as a result of his actions. As far as intentional action is concerned the boundaries of the accordion are the boundaries of the complex intention; and indeed we have the accordion effect for Intentional actions because we have complex intentions that represent the "by means of" relation, both of causal and of other sorts. But the complex intention does not quite set the boundaries of the action, because of the possibility of unintentional actions; and, as I said earlier, I don 't know how to distinguish those unintended results, consequences, upshots, and effects of our intentional actions which are not actions, not even unintentional actions, from those which are unintentional actions.

If we are going to have any use for the concept of a basic action at all, we might say that the top member of any such accordion is a basic action, and we might indeed define a basic action as follows: $A$ is a basic action for an agent $S$ iff $S$ can do $A$ and $S$ can intend to do $A$ without intending to do any other action by 
means of which he intends to do $A$. (For this formulation I am indebted to the work of Charles Taylor, though I don't know if he would accept it.) Notice that this definition would make an action basic only relative to an agent and his skills; what is basic for one agent might not be basic for another. But that may be a useful way to describe the facts: for a good skier making a left tum can be a basic action. He just intends to do it and he does it. For a beginner to make a left turn he must put the weight on the downhill ski while edging it into the slope, stem the uphill ski, then shift the weight from left to right ski, etc., all of which are reports of the content of his intentions in action. For two agents the physical movements might be indistinguishable even though one was performing a-for him-basic action and the other was performing the same action by means of performing a basic action. Furthermore, this definition would have the consequence that for any one agent there may be no sharp dividing line between his basic and nonbasic actions. But, again, that may be the right way to describe the facts.

IV

In this section I will try to show how the account of the relations of intention and action that I have presented will explain the paradoxical asymmetries of Section II.

First, the reason there is a more intimate connection between actions and intentions than there is between, say, beliefs and states of affairs is that actions contain intentions in action as one of their components. An action is a composite entity of which one component is an intention in action. If the composite entity also contains elements which constitute the conditions of satisfaction of the Intentional component in the way described earlier, the agent succeeded in the performance of an intentional action. If not, he only tried but failed. Thus to take our overworked example: the action of my raising my arm consists of two components, the intention in action and the movement of the arm. Take away the first and you don't have an action-only a movement-take away the second and you don't have success, but only a failed effort.

The sense in which we can say that an intentional action is caused by an intention or simply is the condition of satisfaction of an intention can now be made more precise. The condition of satisfaction of a prior intention really is an action, but not all actions are performed as the result of prior intentions. There can be actions without corresponding prior intentions, e.g. when I just haul off and hit somebody without any prior intention to hit him. But there can't be any actions, not even unintentional actions without intentions in action. Actions thus necessarily contain intentions in action, but are not necessarily caused by prior intentions. But the Intentional content of the intention in action is not that it should cause the action, but rather than it should cause the movement (or state) of the agent which is its condition of satisfaction, and the two together, intention in action and movement constitute the action. So it wasn 't quite right to say that an 
intentional action just is the condition of satisfaction of an intention; it was wrong for two reasons: actions don't require prior intentions and though they do require intentions in action, the condition of satisfaction of the intention in action is just the movement or state of the agent, not the action. What it is correct to say, I believc, is that an action is any composite event or state that contains the occurrence of an intention in action. If that intention in action causes its conditions of satisfaction the event or state is a successfully performed intentional action; if not, it is unsuccessful. An unintentional action is an intentional action which has aspects which were not intended in it, i.e. were not presented as conditions of satisfaction of the intention in action. However, lots of things I do unintentionally, e.g. sneezing, are not actions at all, for though they are things I cause, they contain no intentions in action.

We now have a very simple explanation of the Chisholm-style counterexamples to the view that actions which are caused by intentions are intentional actions. In the uncle example the prior intention caused the killing of the uncle, but the killing of the uncle was unintentional. Why? In our analysis we saw there are three stages: the prior intention, the intention in action, and the physical event. The prior intention causes the event by way of causing the intention in action, which causes and presents the event as its conditions of satisfaction. But in the uncle example this middle stage was left out. We did not have the death of the uncle as the condition of satisfaction of any intention in action, and that is why he was killed unintentionally.

There are several such puzzling examples in the philosophical literature on this subject, and I believe the approach I am advocating will account for all those I have seen, because they all rest on a failure to understand intentions in action. Consider the following from Davidson (1973), which he says illustrates the sources of his

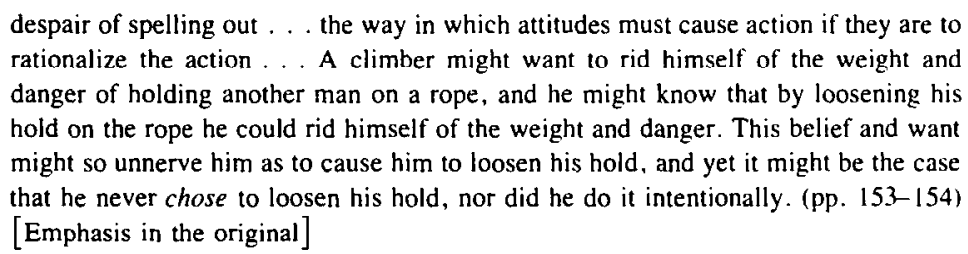

I believe the way to dispel the despair is to recognize the role of the intention in action and to make fully explicit the Intentional contents of the relevant Intentional states. The reason the climber's loosening of his hold is unintentional in the case as described is that he has no intention in action of loosening his hold. There is no moment at which he could say "I am now loosening my hold" as a way of articulating the content of his intention in action i.e. as a way of making explicit the conditions of satisfaction of his intention, even though he might say just that as a way of describing what was happening to him. Even if on the basis of his belief and desire he formed a secondary desire to loosen his hold and this desire caused him to loosen his hold, it is still not an intentional action if he does 
not have an intention in action to loosen his hold. In an intentional action, on the other hand, the standard way the sequence of Intentional states would work is as follows:

$$
\begin{aligned}
& \text { I want (I rid myself of weight and danger) } \\
& \text { I believe (the best way to rid myself of weight } \\
& \text { and danger is to loosen my hold). }
\end{aligned}
$$

And by practical reason this leads to a secondary desire:

$$
\text { I want (I loosen my hold). }
$$

And this leads, either with or without a prior intention, to an intention in action: the climber says to himself "Now!" And the content of his intention in action is:

I am now loosening my hold.

That is:

This intention in action causes my hand

to loosen its hold on the rope.

The whole structure is both Intentional and causal; the sequence of Intentional states causes the bodily movement. There are various problems about how practical reason works, but I must say I do not see any deep mystery here, much less cause for despair in analyzing how Intentionality explains intentional actions.

Another (equally homicidal) example derives from Dan Bennett (see Davidson, 1973, pp. 152-153). A man may try to kill someone by shooting at him. Suppose he misses him, but the shot stampedes a heard of wild pigs which tramples the intended victim to death. In this case the man "s intention in action presents the death of the victim as part of the conditions of satisfaction and the victim dies as a result, but all the same we are reluctant to say that it was an intentional killing. And the reason is obvious. The intention in action had a whole lot of other details about how the killing was to be accomplished as parts of its conditions of satisfaction, and these conditions were not satisfied. Some people have thought that the problem in all these cases has to do with the oddity of the causal sequences, but the causal sequence only matters if it is part of the Intentional content of the intention in action. To see this we can vary the above example as follows: the killer's assistant, knowing about the pigs in advance, tells the killer, "Shoot your gun in that direction and you will kill him." The killer does as instructed with the death of the victim as the result; and in this case the killing is intentional, even though the events are as causally bizarre as in Bennett's original example.

Could we get similar counterexamples where something gets between the intention in action and the event so that, though we could say the intention in action caused the physical event, the action was not intentional? The only plausi- 
ble cases I can think of are cases where some other intention in action intervenes to bring about the event. Thus, suppose that unknown to me my arm is rigged up so that whenever I try to raise it, somebody else causes it to go up, then the action is his, not mine, even though I had the intention in action of raising my arm and in some sense that intention caused my arm to go up. (The reader will recognize this as essentially the Occasionalist solution to the mind-body problem. God does all of our actions for us.)

But this class of potential counterexamples is eliminated in these simple cases by construing relation of the intention in action to its conditions of satisfaction as precluding intervention by other agents or other Intentional states. And that this is the right way to contrue intentions in action is at least indicated by the fact that for such simple cases as raising my arm, when my intentions in action make explicit reference to the intentions of other agents, the actions then become the actions of those agents. Thus suppose I know how my arm is rigged up and I want it to go up. My intention in action then is getting the other agent to raise it. not raising it. My action is getting him to raise it, his action is raising it.

But as long as there is no intervening Intentionality it doesn 't matter how weird the physical apparatus might be. Even if unknown to me my arm is rigged up to a whole lot of electrical wires that go through Moscow and return via San Diego and when I try to raise my arm it activates this whole apparatus so that my arm goes up, all the same, I raise my arm. For some complex acts one can perform the act by getting others to perform it. We say 'Louis XIV built Versailles' but the actual construction was not done by him.

However, this account is still incomplete because there is a class of possible counterexamples I have not yet discussed, cases where the prior intention causes something else which causes the intention in action. Suppose, for example, Bill's intention to kill his uncle causes him to have a stomach ache and his stomach ache makes him so angry that he forgets all about his original intention but in his rage he kills the first man he sees whom he recognizes as his uncle. I believe that such possible counterexamples can also be eliminated, but to do so requires an analysis of Intentional causation that goes beyond the scope of this article.

A final word about desires and beliefs. Nothing in this account is inconsistent with the view that actions are caused by desires, for desires may lead to the formation of prior intentions, often through deliberation, or they may directly cause intentions in action, e.g. I am thirsty so I take a drink of water. But it is at least misleading to say that actions are caused by both desires and beliefs. for beliefs have the wrong direction of fit and they lack the logical connection between cause and effect necessary for the Intentional causation of actions. When beliefs function in the causal account of actions it is characteristically as part of the cause of secondary desires. Thus suppose I want to go to Paris and I believe the only way I can go to Paris is by first buying a plane ticket. Now the way this conjunction of belief and desire functions as the cause of my buying a 
plane ticket is by first causing a secondary desire to buy a plane ticket, through "practical reason." And the way to see this is to note that if I don't have any desire to buy the plane ticket I won't perform the intentional action of buying it, regardless of my beliefs. In the direct way that desires cause actions, beliefs don't cause actions, though in conjunction with primary desires they do cause secondary desires. Nor will it do to say that when my desire causes me to raise my arm it is only because I also have the belief that this is raising my arm, for the fact that this satisfies the desire must already be determined by the desire, since the desire represents its conditions of satisfaction.

\section{REFERENCES}

Chisholm, R. M. Freedom and action. In K. Lehrer (Ed.) Freedom and determinism. New York: Random House, 1966.

Danto, A. Basic actions. In A. R. White (Ed.) The philosophy of action. London: Oxford University Press, 1968

Davidson, D. Freedom to act. In T. Honderich (Ed.) Essays on freedom of action. London: Routledge \& Kegan Paul, 1973.

Feinberg, J. Doing and deserving. Princeton, N.J.: Princeton University Press, 1970.

Hampshire, S. Thought and action. London: Chatto \& Windus, 1959.

Penfield, W. The mystery of mind. Princeton, N.J.: Princeton University Press, 1975.

Searle, J. R. Intentionality and the use of language. In A. Margalit (Ed.) Meaning and use. Dordrecht, Holland: Reidel, 1971.

Searle, J. R. What is an intentional state? Mind, 1978, 88, 74-92.

Weiskrantz, L. Trying to bridge some neurological gaps between monkey and man. British Journal of Psychology, 1977, 68, 431445.

Wittgenstein, L. Philosophical investigations. New York: Macmillan, 1953. 